\title{
Prevalence of Cervical Artery Abnormalities on CTA in Patients with Spontaneous Coronary Artery Dissection: Fibromuscular Dysplasia, Dissection, Aneurysm, and Tortuosity
}

\author{
(D).C. Benson, (D) V.T. Lehman, (D).T. Verdoorn, DD.P. Shlapak, (DS.N. Hayes, and (DM.S. Tweet
}

\begin{abstract}
BACKGROUND AND PURPOSE: Little is known about associations between spontaneous coronary artery dissection and cervical artery abnormalities. This study sought to assess the prevalence of cervical artery abnormalities among patients with spontaneous coronary artery dissection.
\end{abstract}

\begin{abstract}
MATERIALS AND METHODS: A retrospective analysis was completed of patients who underwent CTA neck imaging as part of arterial assessment following the diagnosis of spontaneous coronary artery dissection. The internal carotid and vertebral arteries were evaluated for the presence of fibromuscular dysplasia, dissection and/or pseudoaneurysm, ectasia and/or aneurysmal dilation, atherosclerosis, and webs. Carotid tortuosity was categorized into kinks, loops, coils, and retrojugular and/or retropharyngeal carotid courses; vertebral tortuosity was classified by subjective analysis of severity.
\end{abstract}

RESULTS: Two hundred fourteen patients were included in the final cohort, of whom 205 (95.8\%) were women; the average age was 54.4 years. Fibromuscular dysplasia was the most frequently observed abnormality (83 patients; $38.8 \%$ ), followed by dissections and/or pseudoaneurysms ( $n=28 ; 13.1 \%)$, ectasia and/or aneurysmal dilation $(n=22 ; 10.3 \%)$, and carotid webs $(n=10 ; 4.7 \%)$. At least 1 type of carotid tortuosity was present in 99 patients $(46.3 \%)$. The majority $(n=185 ; 86.4 \%$ ) of patients had no carotid atherosclerosis; and 26 (12.2\%) had mild; 3 (1.4\%), moderate; and 0, severe carotid atherosclerosis.

CONCLUSIONS: The most common abnormality in the cervical artery vasculature of patients with spontaneous coronary artery dissection is fibromuscular dysplasia. Cervical dissections were higher than previously reported but were not observed in most patients.

ABBREVIATIONS: $\mathrm{ACS}=$ acute coronary syndrome; $\mathrm{CTD}=$ connective tissue disorder; FMD = fibromuscular dysplasia; $\mathrm{SCAD}=$ spontaneous coronary artery dissection

S pontaneous coronary artery dissection (SCAD) is an increasingly recognized cause of acute coronary syndrome (ACS), predominantly affecting otherwise healthy young and middleaged women. ${ }^{1,2}$ By definition, it refers to dissection of the coronary artery wall in the absence of trauma, atherosclerosis, or iatrogenic causes. ${ }^{3}$ The resultant intramural hematoma and/or intimal flap can cause substantial luminal narrowing, leading to myocardial ischemia and infarction. Once considered rare, SCAD is now thought to be the cause of up to $4 \%$ of cases of ACS and up to $35 \%$ of cases of ACS in women younger than of 50 years of age. ${ }^{4,5}$ Furthermore, there is evidence that the incidence of SCAD has increased during the past decades. ${ }^{6}$

Received December 18, 2020; accepted after revision February 26, 2021.

From the Departments of Radiology (J.C.B., V.T.L., J.T.V., D.P.S.) and Cardiovascular Medicine (S.N.H., M.S.T.), Mayo Clinic, Rochester, Minnesota.

Please address correspondence to John C. Benson, MD, Mayo Clinic, Department of Radiology, 723 6th St. SW, Rochester, MN 55902; e-mail: benson.john3@mayo.edu

- Indicates open access to non-subscribers at www.ajnr.org

http://dx.doi.org/10.3174/ajnr.A7151
Prior work has reported an association of SCAD with fibromuscular dysplasia (FMD) in various arteries. Less frequently, there may be an association with connective tissue disorders (CTDs) and vasculitides. ${ }^{7,8}$ Peripartum or postpartum women are also thought to be at risk, and both emotional stress and exercise have been offered as precipitating factors. ${ }^{9,10}$ These associations suggest that patients with SCAD have an underlying susceptibility to dissection, related to structural and/or hormonal alterations. Thus, patients are advised to undergo additional imaging to assess additional vascular abnormalities, such as asymptomatic dissection, aneurysms, or evidence of CTDs. ${ }^{3,11}$

Within the cervical carotid vasculature specifically, the aforementioned arterial anomalies have the potential to cause neurologic symptoms. To date, however, little is known about the prevalence of cervical artery anomalies in patients with SCAD. This study aimed to systematically evaluate the cervical artery vasculature in patients with a documented history of SCAD. 


\section{MATERIALS AND METHODS}

\section{Patient Selection}

This study was approved by the local institutional review board. A retrospective review was completed of adult (18 years of age or older) patients included in the Mayo Clinic SCAD Registry and evaluated at our institution between September 2011 and January 2015 who had CTA imaging of the neck vasculature as part of recommended screening for arteriopathy (patients with SCAD, after being stabilized, typically undergo CTA screening for additional arterial abnormalities). ${ }^{3,11}$ SCAD was nearly always diagnosed when a patient presenting with ACS was found to have a dissection at the time of coronary angiography, which is the criterion standard for diagnosis. The diagnosis of SCAD was confirmed by review of coronary angiograms by at least 2 experienced interventional cardiologists. Patients with atherosclerotic, traumatic, or iatrogenic dissection were excluded, as were patients with nondiagnostic imaging (eg, due to artifacts). Patients who did not survive sudden cardiac death and were diagnosed at postmortem examination were not included. The Mayo Clinic SCAD Registry is described in more detail elsewhere. ${ }^{12}$ Repeat and follow-up CTAs were not included as part of this analysis. MRAs were also not included to optimize the homogeneity of imaging interpretation.

\section{CTA Protocol}

Most imaging was performed on a 128-section multidetector scanner (Somatom Definition Flash; Siemens). For all examinations, Omnipaque 350 (GE Healthcare) was used, administered at $4 \mathrm{~mL} / \mathrm{s}$, (total volume, $100 \mathrm{~mL}$ ). Contrast administration was followed by a flush of normal saline, administered at $4 \mathrm{~mL} / \mathrm{s}$ (total volume, $35 \mathrm{~mL}$ ). Bolus tracking at the level of the aortic arch was used for automatic contrast administration. Anatomic coverage for CTA of the neck was from the carina to the sella; for CTA of the head and neck, the coverage was from the carina to the vertex. Tube current was set to $194 \mathrm{mAs}$, and tube voltage was set to $120 \mathrm{kV}$. Section thickness was $0.75 \mathrm{~mm}$; FOV, $250 \mathrm{~mm}$; and pitch, 0.6. Images were reconstructed and evaluated in all 3 planes (axial, sagittal, and coronal).

\section{Imaging Analysis}

Each CTA neck examination was assessed for multiple findings by 1 of 4 neuroradiologists (J.C.B., V.T.L., J.T.V., D.P.S.); 55-56 examinations were evaluated by each neuroradiologist. Reviewers were not blinded to the diagnosis of SCAD at the time of imaging assessment. The reviewers agreed on the assessment of all imaging characteristics before review to ensure interobserver consistency.

The carotid arteries were evaluated for the presence or absence of FMD, dissection and/or pseudoaneurysm, aneurysm/ ectasia, atherosclerosis, tortuosity, a retrojugular or retropharyngeal course, or intraluminal web. Identification of FMD was based on observation of either focal FMD (focus of nonatherosclerosis narrowing, often with distal/poststenotic arterial dilation) or multifocal FMD (segmental luminal irregularity, the so-called string of beads sign). ${ }^{13}$ The presence or absence of "multivessel" FMD (defined by the international consensus as being focal or multifocal FMD in one vascular bed, with FMD, aneurysm, dissection, or tortuosity in another vascular bed) was not assessed in this study. ${ }^{13}$ Instead, the study specifically assessed whether various abnormalities were present in specific vascular beds.

Dissections, particularly when chronic, share many imaging features with pseudoaneurysms. Thus, the term "dissecting pseudoaneurysm" is often used to describe such findings, explaining why these findings were combined. Dissections and/ or pseudoaneurysms were defined as being either an intimal flap, sudden arterial caliber change with distal irregularity, or tapering occlusion ("flame sign") or a focal outpouching of the artery (typically along 1 side of the lumen) in addition to at least 1 of the aforementioned findings. Aneurysms and ectasia were defined as either focal areas of arterial dilation of $>50 \%$ of the adjacent luminal diameter (ie, either ectasia or "fusiform" aneurysms) or a focal outpouching along an arterial wall ("saccular" aneurysm).

Webs were presumed on the basis of a classic imaging appearance: a thin, noncalcified focus of tissue projecting into the vessel lumen from the posterior wall of the carotid artery (typically within the carotid bulb). Although webs are thought to represent a variant of FMD, as discussed below, they were considered to be distinct from FMD for the purposes of this review. Carotid atherosclerosis was based on the severity of luminal stenosis: "mild" was $<25 \%$ narrowing, "moderate" was $25 \%-74.9 \%$, and "severe" was $\geq 75 \%$, while "none" referred to the absence of any identifiable plaque.

Arterial tortuosity was divided into 3 previously described subtypes, as the following: "Kink" was a singular acute angulation of the ICA $\left(\leq 90^{\circ}\right)$, a "loop" was an S- or C-shaped curvature in which 2 adjacent turns both had acute angulations $\left(\leq 90^{\circ}\right)$, and a "coil" was a complete $360^{\circ}$ turn in the vessel. ${ }^{14,15}$ Retrojugular and retropharyngeal pathways of the ICA were also considered subtypes of tortuosity because their presence implied a greater degree of horizontal distortion of the arterial pathway. Both pathways were similarly evaluated on the basis of prior definitions: A "retrojugular" ICA took a course in which $>50 \%$ of the cross-sectional area of the artery was behind or lateral to the adjacent internal jugular vein, while a "retropharyngeal" ICA had $\geq 50 \%$ of its cross-sectional lumen located behind or medial to the lateral edge of the pharynx. ${ }^{14,16}$ Vertebral arteries were assessed for FMD, dissection and/or pseudoaneurysm, aneurysm/ectasia, and a subjective degree of tortuosity (categorized as none, mild, moderate, and severe). In cases of asymmetric severity of either carotid atherosclerosis or vertebral tortuosity, the side with greater severity was considered for purposes of statistical assessment (eg, if atherosclerosis severity was moderate on the right and mild on the left, the overall severity was considered moderate).

\section{Electronic Medical Review and Data Analysis}

Patient demographics and comorbidities were assessed through retrospective review of patients' electronic medical records. Documentation of extracoronary FMD (outside the cerebrovascular system) was also noted, typically diagnosed at the time of coronary angiography. All data were analyzed using the statistical software package JMP, Version 13.0 (SAS Institute). Continuous data are summarized as mean (SD), while categoric variables are expressed as frequency (percentage). 


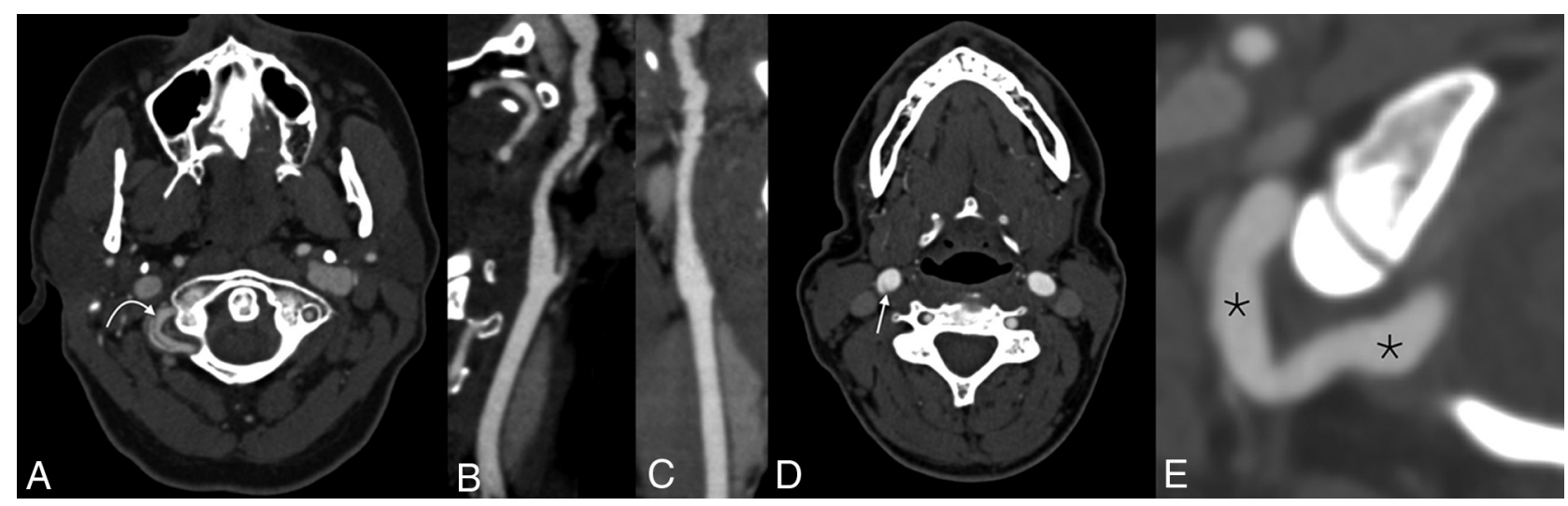

FIG 1. Examples of cervical artery abnormalities noted in patients with SCAD. Axial CTA $(A)$ demonstrates a right vertebral artery dissection (curved arrow). Reformatted sagittal $(B)$ and coronal $(C)$ images show multifocal FMD of the right ICA. Axial CTA (D) demonstrates a web in the right ICA bulb (straight arrow). Reformatted axial CTA (E) shows ectasia of the distal right vertebral artery (asterisks).

Table 1: Prevalence of various imaging findings in patients with SCAD $^{a}$

\begin{tabular}{lc}
\hline \multicolumn{1}{c}{ Findings } & No. (\%) \\
\hline FMD & $83 / 214(38.8 \%)$ \\
Dissection and/or pseudoaneurysm & $28 / 214(13.1 \%)$ \\
Aneurysm/ectasia & $22 / 214(10.3 \%)$ \\
Carotid web & $10 / 214(4.7 \%)$ \\
$1+$ type of carotid tortuosity & $99 / 214(46.3 \%)$ \\
Atherosclerosis & \\
None & $185 / 214(86.4 \%)$ \\
Mild & $26 / 214(12.2 \%)$ \\
Moderate & $3 / 214(1.4 \%)$ \\
Severe & $0 / 214(0.0 \%)$ \\
Vertebral tortuosity & $124 / 214(57.9 \%)$ \\
None & $64 / 214(29.9 \%)$ \\
Mild & $22 / 214(10.3 \%)$ \\
Moderate & $4 / 214(1.9 \%)$ \\
Severe & \\
\hline a FMD, dissection, pseudoaneurysm, and aneurysm/ectasia numbers reflect the \\
number of patients with those findings in either the carotid or vertebral artery. \\
Webs were only assessed in the carotid arteries because they are considered to \\
be rarely present in the vertebral arteries. Subtypes of carotid tortuosity include \\
kinks, loops, coils, and retropharyngeal and retrojugular courses. Carotid athero- \\
sclerosis and vertebral tortuosity reflect the more severe side, if asymmetry \\
existed.
\end{tabular}

\section{RESULTS}

\section{Patient Characteristics}

Of 221 patients with SCAD and CTA neck imaging, 7 were excluded because the obtained images were nondiagnostic. The final cohort, therefore, comprised 214 patients, 205 (95.8\%) of whom were women. The average age was 54.4 (SD, 10.6) years. The average time between the initial SCAD event and CTA neck imaging was 27.9 (SD, 43.8) months.

The most common comorbidities were a documented history of hypertension and hyperlipidemia (both in 71 patients [33.2\%]). Three patients (1.4\%) had diabetes, 60 patients $(28.2 \%)$ had either current or prior tobacco use, and 9 patients had a known connective tissue disorder ( 4 with Raynaud's phenomenon, 1 mixed connective tissue disorder, 1 Ehlers-Danlos syndrome, 1 rheumatoid arthritis, 1 Sjogren syndrome, and 1 undefined).

Regarding a documented history of extracoronary FMD outside the cerebrovascular system, 108 (50.5\%) had imaging evidence of FMD, 18 (8.4\%) had a type of non-FMD extracoronary vascular abnormality (dissection, aneurysm, ectasia/dilation, or tortuosity that did not meet the criteria for multifocal FMD), and the remainder had no FMD noted or documented. The most common location of extracoronary, extracerebrovascular FMD was the renal arteries $(69 ; 32.2 \%)$, followed by the iliac arteries (common, internal, or external) $(51 ; 23.8 \%)$, femoral arteries $(11 ; 5.1 \%)$, celiac artery $(10 ; 4.7 \%)$, superior mesenteric artery $(5 ; 2.3 \%)$, splenic artery $(5 ; 2.3 \%)$, and brachial artery $(1 ; 0.5 \%)$.

\section{Imaging Analysis}

Examples of various abnormalities are shown in Fig 1. The most common abnormality found within the arterial vasculature of patients with SCAD was FMD (Tables 1 and 2). One hundred seven $(50.0 \%)$ patients had no web, FMD, dissection and/or pseudoaneurysm, or aneurysm and/or ectasia in any of the neck vessels. Although the severity of FMD was not formally graded, some cases were subjectively mild. Similarly, some webs were subjectively subtle. Among patients with SCAD, the majority $(185 / 214 ; 86.4 \%)$ had no atherosclerosis and 26/214 (12.2\%) had mild, 3 ( $1.4 \%$ ) had moderate, and no patients had severe atherosclerotic narrowing.

A subtype of tortuosity (kink, loop, or coil) was present in either carotid artery in 56/214 (26.2\%) patients (Fig 2). When we considered retropharyngeal and retrojugular courses as additional phenotypes of tortuosity, some tortuosity subtype (kink, loop, coil, retropharyngeal, retrojugular) was present in either carotid artery in 99/214 (46.3\%) patients. Of these, kinks were the most common and observed in 15/214 (7.0\%) right carotid arteries and 14/214 (6.5\%) left carotid arteries. These were followed by loops (present in $9.3 \%$ of both right and left carotid arteries) and coils (present in 2.8\% of right carotid and $2.3 \%$ of left carotid arteries). Eight patients (3.7\%) had kinks of both ICAs, 14 patients (6.5\%) had loops of both ICAs, and 1 patient $(0.5 \%)$ had coils in both ICAs. The right ICA followed a retrojugular course in 17 patients and a retropharyngeal course in 8 patients; the left ICA followed a retrojugular course in 54 patients and a retropharyngeal course in 4 patients. Most patients with SCAD had no vertebral tortuosity (124/214; 57.9\%); 64/214 
Table 2: Prevalence of FMD, dissection and/or pseudoaneurysm, aneurysm/ectasia, and webs based on arterial involvement ${ }^{\mathrm{a}}$

\begin{tabular}{|c|c|c|c|c|c|c|}
\hline & $\begin{array}{l}\text { Right Carotid } \\
\text { Artery }\end{array}$ & $\begin{array}{l}\text { Left Carotid } \\
\text { Artery }\end{array}$ & $\begin{array}{l}\text { Both Carotid } \\
\text { Arteries }\end{array}$ & $\begin{array}{l}\text { Right Vertebral } \\
\text { Artery }\end{array}$ & $\begin{array}{l}\text { Left Vertebral } \\
\text { Artery }\end{array}$ & $\begin{array}{c}\text { Both Vertebral } \\
\text { Arteries }\end{array}$ \\
\hline FMD & $56(25.2 \%)$ & 49 (22.9\%) & 39 (18.2\%) & $30(14.0 \%)$ & $32(15.0 \%)$ & $22(10.3 \%)$ \\
\hline $\begin{array}{l}\text { Dissection and/or } \\
\text { pseudoaneurysm }\end{array}$ & $5(2.3 \%)$ & $8(3.7 \%)$ & $0(0.0 \%)$ & $8(3.7 \%)$ & $12(5.6 \%)$ & $1(0.5 \%)$ \\
\hline Aneurysm/ectasia & $16(7.5 \%)$ & $13(6.1 \%)$ & $8(3.7 \%)$ & $4(1.9 \%)$ & $3(1.4 \%)$ & $1(0.5 \%)$ \\
\hline Web & $6(2.8 \%)$ & $6(2.8 \%)$ & $0(0.0 \%)$ & NA & & \\
\hline
\end{tabular}

Note:-NA indicates not applicable.

${ }^{a}$ The presence or absence of webs within the vertebral arteries was not assessed because they are classically found in the carotid bulbs. Data are No. (\%).

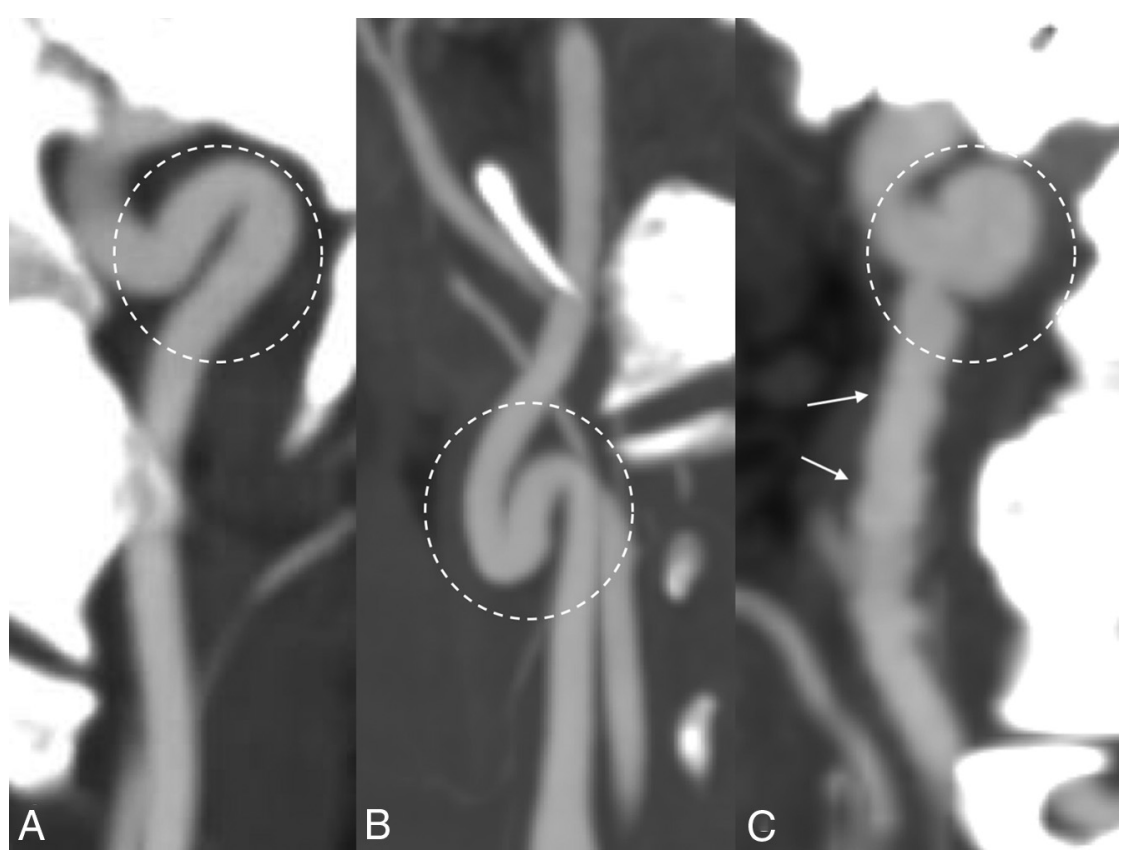

FIG 2. Examples of tortuosity subtypes. Arterial kink (A) (a single arterial angulation of $\leq 90^{\circ}$ ), loop (B) (2 adjacent acute angulations of the vessel), and coil (C) (complete $360^{\circ}$ turn) are all shown. Also note the beaded irregularity of the vessel in C, compatible with FMD (arrows). come from angiography, particularly of the iliac and renal arteries. ${ }^{19}$ Prior data dedicated to analysis of the cervical artery vasculature, conversely, are relatively scant. For example, Saw et $\mathrm{al}^{9}$ found imaging evidence of cerebrovascular (not specifically defined as extraor intracranial) $\mathrm{FMD}$ in $46.5 \%$ of 43 patients. A separate study by Saw et $\mathrm{al}^{20}$ included 327 patients. The authors found that $62.7 \%$ of patients had FMD. Approximately $49 \%$ of the observed FMDs involved the cerebrovasculature.

The high prevalence of FMD in patients with SCAD offers an alluring prospect for explaining the pathogenesis of coronary artery dissections. Histologically, FMD is considered a nonatherosclerotic, noninflammatory thickening of arterial wall layers that predisposes the vessel to both dissection and aneurysms and vascular ectasia. $^{21,22}$ Furthermore, Olin et $\mathrm{al}^{23}$ found that nearly $20 \%$ of patients with FMD had a history of TIA or stroke. Thus, the prevalence of cervi-
(29.9\%) had mild, $22 / 214$ (10.3\%) had moderate, and $4 / 214$ (1.9\%) had severe vertebral tortuosity.

\section{DISCUSSION}

This study is the most robust analysis of detailed cervical imaging findings among patients with SCAD and establishes the prevalence of cervical artery vasculature abnormalities among such patients on CTA. Pertinent findings of this study include finding a high prevalence of cervical FMD among patients with SCAD, identifying a subset of patients with isolated cervical artery dissection, and finding a high prevalence of arterial webs, ectasia, and/ or aneurysms in the absence of cervical FMD. These findings have implications for patient counseling and image interpretation, offer insight into the pathogenesis of SCAD-related arterial manifestations, and reinforce the importance of cervical artery imaging surveillance in patients with SCAD.

The current study found that nearly $40 \%$ of patients with SCAD had imaging evidence of cervical FMD. Prior work has indicated that noncoronary FMD exists in as many as $72 \%-86 \%$ of patients with SCAD. ${ }^{1,17,18}$ However, these evaluations have cal FMD in patients with SCAD suggests that this patient subset may be at increased risk of such cerebrovascular manifestation, though additional work will be needed to further characterize the association.

The higher rate of carotid webs among patients with SCAD is important because this finding may also be related to FMD and is increasingly associated with otherwise cryptogenic strokes. ${ }^{24,25}$ Some authors have suggested that webs represent rare variants of the intimal subtype of FMD. ${ }^{26,27}$ However, an international consensus article reinforced webs as being likely distinct entities from FMD. ${ }^{13}$ Nevertheless, the nearly $5 \%$ prevalence of webs in this study suggests that radiologists should carefully scrutinize CTA examinations in this population for this finding and clinicians should note the potential risk for stroke. Additional work with even larger numbers of patients would be needed to confirm this association because this was identified in only a handful of patients and the prevalence of webs in a typical population is around $1 \% .^{25,28-30}$

While prior work has found the presence of carotid dissection in SCAD to be in the range of $2.5 \%-5 \%$, the current study demonstrates a prevalence of more than twice that, suggesting that 
dissection is more common than previously suspected. ${ }^{31,32}$ Nonetheless, the relatively low prevalence of dissection compared with FMD at a single time point examination in the current study may provide some reassurance of cerebrovascular risk for patient counseling for many patients. However, further evaluation is needed regarding the rate of dissection and related neurologic sequelae, with long-term longitudinal data specific to patients with SCAD. Current studies focused on patients with FMD show that clinical complications from cerebrovascular FMD are uncommon. ${ }^{33,34}$

The lack of arterial tortuosity in patients with SCAD is interesting, because coronary tortuosity has been shown in prior studies to be highly prevalent in patients with SCAD and exists at higher rates in patients with SCAD than in age- and sex-matched controls. ${ }^{35,36}$ Although a relatively nonspecific finding, arterial tortuosity is increased in patients with many types of CTD to varying degrees. ${ }^{37}$ CTDs, in turn, are associated with arterial dissections. ${ }^{15}$ It is, therefore, reasonable that the higher level of tortuosity seen in coronary arteries in patients with SCAD is related to underlying CTDs and plays a role in the pathogenesis of dissection. Although it remains uncertain why the current study did not demonstrate a higher prevalence of tortuosity in the patients with SCAD, this topic could be further addressed in future analyses.

Finally, moderate and severe atherosclerosis was extremely rare in patients with SCAD, occurring in $1.4 \%$ and $0 \%$ of patients, respectively. Prior studies have shown patients with SCAD to have a low prevalence of atherosclerotic disease. ${ }^{38}$ Certainly, the relatively young age and female predominance of patients with SCAD may play a role. However, recent studies have also offered a genetic explanation. SCAD is related to the PHACTR1/EDN1 genetic locus, and a risk allele at this locus is associated with both SCAD and FMD and is opposite to the risk allele at this locus that increases the risk of coronary artery disease and myocardial infarction. ${ }^{38,39}$ Genetic susceptibility to FMD and SCAD could, therefore, confer protection against the atherosclerotic changes that lead to coronary artery disease/ myocardial infarction.

This study shares the limitations of all retrospective analyses. In addition, though CTA is a noninvasive approach to studying the prevalence of arteriopathy in SCAD, this study is limited by the sole reliance on CTA imaging evidence rather than histologic confirmation or invasive angiography. There is also an inevitable selection bias among those patients who were imaged, even though performance of comprehensive arterial imaging is encouraged at least once among all patients with history of SCAD. Next, although most imaging characteristics were defined by specific criteria, vertebral artery tortuosity was subjectively evaluated by different reviewers, thus raising the possibility that such assessments were limited by interobserver variability. In addition, because a history of neurologic events was not assessed, it is uncertain to what degree the observed abnormalities were associated with symptomatology. Finally, the lack of clinical data in this article prevents discussion on whether the observed findings were symptomatic or incidental. This type of analysis could be a topic of future studies.

\section{CONCLUSIONS}

This study represents the most robust comprehensive review of cervical artery abnormalities in patients with SCAD. CTA evidence of carotid and/or vertebral artery FMD was found in a substantial subset of patients with SCAD, offering a possible mechanism by which the coronary arteries of such patients are prone to dissection. Some patients with SCAD also demonstrate cervical artery webs (likely a subset of FMD) and ectasia and aneurysms. The burden of dissection was higher than that in prior studies but still affected just $>10 \%$ of patients. Half of patients with SCAD will not have any of these findings on CTA, which may provide reassurance. Nevertheless, the prevalence of abnormalities supports the practice of routine screening for arterial abnormalities in this population.

\section{ACKNOWLEDGMENTS}

The authors thank the Mayo Clinic "Virtual" Multicenter SCAD Registry participants who volunteered their data for this study.

Disclosures: Marysia S. Tweet-RELATED: Grant: National Institutes of Health Building Interdisciplinary Research Careers in Women's Health, Comments: National Institutes of Health Building Interdisciplinary Research Careers in Women's Health Scholar during part of the time spent on this project.* *Money paid to the institution.

\section{REFERENCES}

1. Gilhofer TS, Saw J. Spontaneous coronary artery dissection: update 2019. Curr Opin Cardiol 2019;34:594-602 CrossRef Medline

2. Rashid HN, Wong DT, Wijesekera $\mathrm{H}$, et al. Incidence and characterisation of spontaneous coronary artery dissection as a cause of acute coronary syndrome: a single-centre Australian experience. Int J Cardiol 2016;202:336-38 CrossRef Medline

3. Hayes SN, Kim ES, Saw J, et al. American Heart Association Council on Peripheral Vascular Disease; Council on Clinical Cardiology; Council on Cardiovascular and Stroke Nursing; Council on Genomic and Precision Medicine; and Stroke Council. Spontaneous coronary artery dissection: current state of the science: a scientific statement from the American Heart Association. Circulation 2018;137:e52357 CrossRef Medline

4. Saw J. Spontaneous coronary artery dissection. Can J Cardiol 2013;29:1027-33 CrossRef Medline

5. Saw J, Aymong E, Mancini GB, et al. Nonatherosclerotic coronary artery disease in young women. Can J Cardiol 2014;30:814-19 CrossRef Medline

6. Kronzer VL, Tarabochia AD, Lobo Romero AS, et al. Lack of association of spontaneous coronary artery dissection with autoimmune disease. J Am Coll Cardiol 2020;76:2226-34 CrossRef Medline

7. Henkin S, Negrotto SM, Tweet MS, et al. Spontaneous coronary artery dissection and its association with heritable connective tissue disorders. Heart Br Heart 2016;102:876-81 CrossRef Medline

8. Kaadan M, Ihsan MacDonald C, Ponzini F, et al. Prospective cardiovascular genetics evaluation in spontaneous coronary artery dissection. Circ Genom Precis Med 2018;11:e001933 CrossRef Medline

9. Saw J, Ricci D, Starovoytov A, et al. Spontaneous coronary artery dissection: prevalence of predisposing conditions including fibromuscular dysplasia in a tertiary center cohort. JACC Cardiovasc Interv 2013;6:44-52 CrossRef Medline

10. Pabla JS, John L, McCrea WA. Spontaneous coronary artery dissection as a cause of sudden cardiac death in the peripartum period. BMJ Case Rep 2010;2010:bcr0520102994 CrossRef Medline

11. European Society of Cardiology, Acute Cardiovascular Care Association. SCAD study group: a position paper on spontaneous coronary artery dissection. European Heart Journal. Oxford Academic. 
https://academic.oup.com/eurheartj/article/39/36/3353/4885368. Accessed November 16, 2020.

12. Tweet MS, Young KA, Best PJ, et al. Association of pregnancy with recurrence of spontaneous coronary artery dissection among women with prior coronary artery dissection. JAMA Netw Open 2020;3:e2018170 CrossRef Medline

13. Gornik HL, Persu A, Adlam D, et al. First international consensus on the diagnosis and management of fibromuscular dysplasia. Vasc Med Lond Med 2019;24:164-89 CrossRef Medline

14. Barbour PJ, Castaldo JE, Rae-Grant AD, et al. Internal carotid artery redundancy is significantly associated with dissection. Stroke 1994;25:1201-06 CrossRef Medline

15. Kim ST, Brinjikji W, Lehman VT, et al. Association between carotid artery tortuosity and carotid dissection: a case-control study. $J$ Neurosurg Sci 2018;62:413-17 CrossRef Medline

16. Benson JC, Brinjikji W, Messina SA, et al. Cervical internal carotid artery tortuosity: A morphologic analysis of patients with acute ischemic stroke. Interv Neuroradiol 2020;26:216-21 CrossRef Medline

17. Saw J, Poulter R, Fung A, et al. Spontaneous coronary artery dissection in patients with fibromuscular dysplasia: a case series. Circ Cardiovasc Interv 2012;5:134-37 CrossRef Medline

18. Gilhofer TS, Saw J. Spontaneous coronary artery dissection: a review of complications and management strategies. Expert Rev Cardiovasc Ther 2019;17:275-91 CrossRef Medline

19. Rogowski S, Maeder MT, Weilenmann D, et al. Spontaneous coronary artery dissection: angiographic follow-up and long-term clinical outcome in a predominantly medically treated population. Catheter Cardiovasc Interv Off Interv 2017;89:59-68 CrossRef Medline

20. Saw J, Humphries K, Aymong E, et al. Spontaneous coronary artery dissection: clinical outcomes and risk of recurrence. J Am Coll Cardiol 2017;70:1148-58 CrossRef Medline

21. Varennes L, Tahon F, Kastler A, et al. Fibromuscular dysplasia: what the radiologist should know: a pictorial review. Insights Imaging 2015;6:295-307 CrossRef Medline

22. Harriott AM, Zimmerman E, Singhal AB, et al. Cerebrovascular fibromuscular dysplasia. Neurol Clin Pract 2017;7:225-36 CrossRef Medline

23. Olin JW, Froehlich J, Gu X, et al. The United States Registry for Fibromuscular Dysplasia: results in the first 447 patients. Circulation 2012;125:3182-90 CrossRef Medline

24. Vercelli GG, Campeau NG, Macedo TA, et al. De novo formation of a carotid web: case report. J Neurosurg 2018 Nov 1. [Epub ahead of print] CrossRef Medline

25. Haussen DC, Grossberg JA, Bouslama M, et al. Carotid web (intimal fibromuscular dysplasia) has high stroke recurrence risk and is amenable to stenting. Stroke 2017;48:3134-37 CrossRef Medline
26. Priyadarshni S, Neralla A, Reimon J, et al. Carotid webs: an unusual presentation of fibromuscular dysplasia. Cureus 2020;12:e9549 CrossRef Medline

27. Zhang AJ, Dhruv P, Choi P, et al. A systematic literature review of patients with carotid web and acute ischemic stroke. Stroke 2018;49:2872-76 CrossRef Medline

28. Sajedi PI, Gonzalez JN, Cronin CA, et al. Carotid bulb webs as a cause of "cryptogenic" ischemic stroke. AJNR Am J Neuroradiol 2017;38:1399-1404 CrossRef Medline

29. Wojcik K, Milburn J, Vidal G, et al. Carotid webs: radiographic appearance and significance. Ochsner J 2018;18:115-20 CrossRef Medline

30. Choi PM, Singh D, Trivedi A, et al. Carotid webs and recurrent ischemic strokes in the era of CT angiography. AJNR Am J Neuroradiol 2015;36:2134-39 CrossRef Medline

31. Prasad M, Tweet MS, Hayes SN, et al. Prevalence of extracoronary vascular abnormalities and fibromuscular dysplasia in patients with spontaneous coronary artery dissection. Am J Cardiol 2015;115:167277 CrossRef Medline

32. McGrath-Cadell L, McKenzie P, Emmanuel S, et al. Outcomes of patients with spontaneous coronary artery dissection. Open Heart 2016;3:e000491 CrossRef Medline

33. Touzé E, Southerland AM, Boulanger M, et al. Fibromuscular dysplasia and its neurologic manifestations: a systematic review. JAMA Neurol 2019;76:217-26 CrossRef Medline

34. Kadian-Dodov D, Goldfinger JZ, Gustavson S, et al. Natural history of cervical artery fibromuscular dysplasia and associated neurovascular events. Cerebrovasc Dis Basel Dis 2018;46:33-39 CrossRef Medline

35. Eleid MF, Guddeti RR, Tweet MS, et al. Coronary artery tortuosity in spontaneous coronary artery dissection: angiographic characteristics and clinical implications. Circ Cardiovasc Interv 2014;7:65662 CrossRef Medline

36. Ciurică S, Lopez-Sublet M, Loeys BL, et al. Arterial tortuosity. Hypertension 2019;73:951-60 CrossRef Medline

37. Welby JP, Kim ST, Carr CM, et al. Carotid artery tortuosity is associated with connective tissue diseases. AJNR Am J Neuroradiol 2019;40:1738-43 CrossRef Medline

38. Adlam D, Olson TM, Combaret N, et al. CARDIoGRAMPlusC4D Study Group. Association of the PHACTR1/EDN1 genetic locus with spontaneous coronary artery dissection. J Am Coll Cardiol 2019;73:58-66 CrossRef Medline

39. Kiando SR, Tucker NR, Castro-Vega LJ, et al. PHACTR1 is a genetic susceptibility locus for fibromuscular dysplasia supporting its complex genetic pattern of inheritance. PLoS Genet 2016;12: e1006367 CrossRef Medline 